\title{
Communication between the right pulmonary artery and left atrium with aneurysm formation
}

\author{
Masahide Chikada, MD · Arata Murakami, MD \\ Kou Takeuchi, MD · Shinichi Takamoto, MD
}

Received: 22 January 2007 / Accepted: 27 November 2007

(C) The Japanese Association for Thoracic Surgery 2008

\section{Erratum to: Gen Thorac Cardiovasc Surg (2008) 56:177-179 \\ DOI 10.1007/s11748-007-0210-y}

We regret that the published version of this article contained an error in the sixth sentence of the last paragraph in the Discussion section, on page 179. The sentence should read as follows:

"We selected a median sternotomy and cardiopulmonary bypass because the aneurysm was large and the connection from the left atrium to the aneurysm was too wide to allow simple division or catheter-based closure."

This online version of the original article can be found at http://dx.doi.org/10.1007/s11748-007-0210-y.

M. Chikada $(\square)$

Department of Cardiovascular Surgery, St. Marianna University, 2-16-1 Sugao, Miyamae-ku, Kawasaki 216-8511, Japan

Tel. +81-44-977-8111; Fax +81-44-976-5792

e-mail: chikada-circ@umin.ac.jp

A. Murakami $\cdot$ K. Takeuchi $\cdot$ S. Takamoto

Department of Cardiac Surgery, The University of Tokyo, Tokyo, Japan 